\title{
Description of Measurements on Biogas Stations
}

\author{
Ladislav Novosad, Zdenek Hradilek
}

\begin{abstract}
This paper focuses mainly on performance analysis for three biogas stations situated within the territory of the Czech Republic. This paper contains basic details of the individual biogas stations as well as description of their types. It also refers to the general description of the measurement gauge involved, with specifications of its potential use. The final part of this paper deals with the analysis of course data obtained, with special regard to voltage, current, active power and reactive power data.)
\end{abstract}

Index Terms - biogas station; power analysis; measurement database; black out; co-generation units; distribution grid

\section{INTRODUCTION}

$\mathrm{T}$ he distribution networks (DN) have experienced the rise in volumes of electric power generated by renewable energy resources (RES) over the recent years. Vast majority of these resources work within the distribution network on decentralized basis and this practice brings a lot of new problems. Such problems are due to the very principle employed by certain resources. The dependency on weather conditions among photovoltaic and wind power plants would be a typical example. The question is how to ensure safe and stable operation or even development of such system. That is why one needs to know characteristics of particular RES, also including the biogas stations (BS). The reason above is therefore addressed by this paper with respect to operation of BS and provision of details referring to the variability of output produced over time.

\section{DESCRIPTION OF MEASUREMENT}

These requirements were accommodated by several longterm measurements conducted right at biogas stations. These BS are situated at three various locations within the territory of Czech Republic, serving as both resources of electric power as well as heat. The generated heat is extracted from combustion products and cooling of the co-generation units by means of heat exchangers. It is then used for heating applied in BS technologies, fermenters, adjacent farm and office buildings. Nevertheless, most of the thermal energy is wasted, and conducted away to the surroundings through forced ventilation using electric fans and coolers. The utilization of thermal energy is not the primary aim of this article, and it is therefore not discussed further.

The measurement at each of the three biogas stations was conducted using the automatic digital measurement devices the network analyzer BK ELCOM ENA 330 and Monitor distribution grids MDS-U(MDS10). This is a complete systems for monitoring and analysis of electric power quality. The devices was employed to record effective values of phase voltage and current in one-minute increments. The voltage readings were taken right from the bus bars inside the main distribution board of BS; monitoring of current was performed using flexible coils - AmpFLEX. The device then completed calculations of remaining values, as the active or reactive power, as well as the apparent power automatically and saved these details in its internal memory.

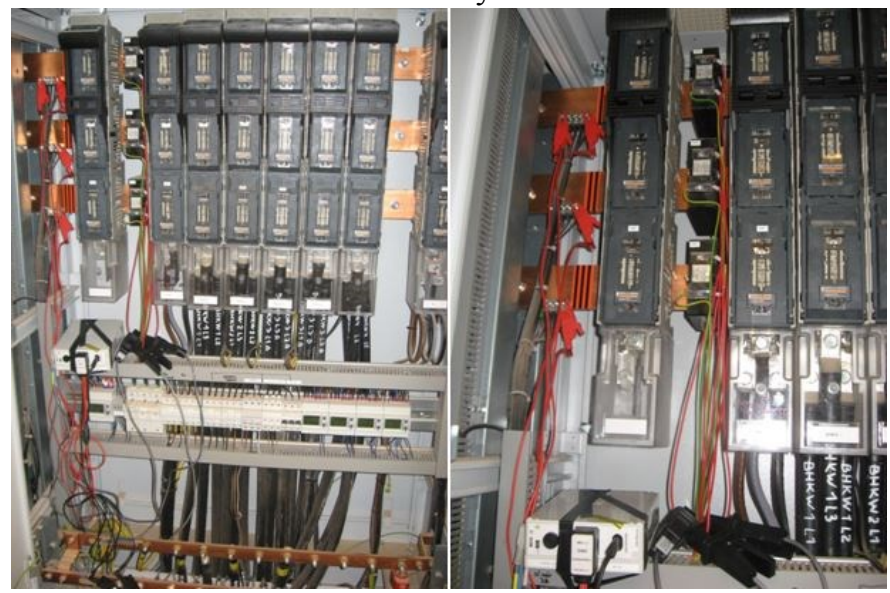

Fig. 1. Demonstration of a connection measurement equipment in the BS 1

The electric power generated by all three BSs is supplied to the main distribution board, which is linked with a transformer station rated for $0.4 / 22 \mathrm{kV}$ further connected to the $22 \mathrm{kV}$ distribution grid (DG).

The measurement of electric values also involved assessment of electric power quality in compliance with CSN EN 50160. The characteristics subject to assessment included mainly the magnitude and drops of voltage, the total harmonic distortion of voltage, flicker and voltage unbalance. 


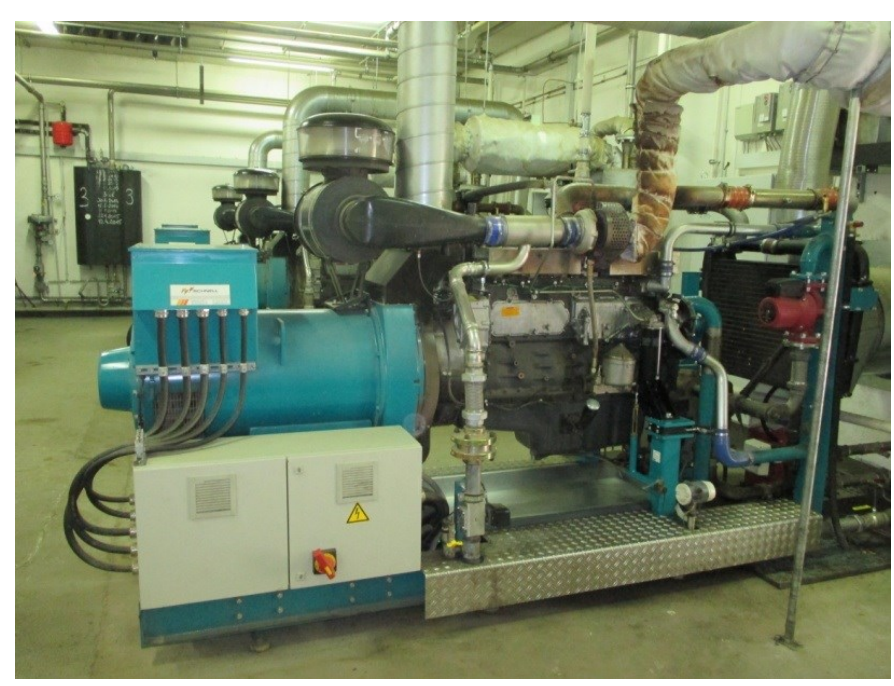

Fig. 2. Demonstration of a co-generation unit in the BS 1 biogas station

The network analyzer BK ENA 330 used in this case complies with the requirements focused on measurement equipment and the measurement procedure set forth by standards ČSN EN 50160, ČSN EN 61000-4-7, ČSN EN 61000-4-15 and ČSN EN 61000-4-30. [4]. This research was partially supported by the SGS grant from VSB - Technical University of Ostrava (No. SP2016/95).

\section{A. Biogas station at location 1}

The first measurement was conducted at the BS in location 1 (BS 1). The biogas station itself is situated within the premises of a piggery farming enterprise. The input raw material for the wet fermentation process is then represented mainly by pig's slurry and maize silage. This BS provides the installed electrical capacity of $1090 \mathrm{~kW}$. Transformation of biogas into electric power is handled by four co-generation units. There are three identical compression ignition units delivering the output of $250 \mathrm{kWe}$ and one spark ignition unit with the output of 340 kWe. $(1$ x KGJ: Agrogen type BGA $222-340 \mathrm{kWe}$ and $3 \mathrm{x}$ CGU: Schnell type ES 2507 - 250k We).

- The measurement was conducted in the following period: from 9.1.2014 to 24.2.2014 - 58 days in total

\section{B. Biogas station at location 2}

Another measured BS was the one in location 2 (BS 2). This station forms a part of the collective farm nearby; this is also the point for supply of the input raw materials for fermentation. The main input raw materials for wet fermentation at this BS is grass silage, wheat silage, maize silage, pig's or cow's slurry. This BS provides the installed electrical capacity of $1186 \mathrm{kWe}$. Conversion of biogas into electric power is handled by two cogeneration units GE Jenbacher JGS 312 GS-B.LC with the electrical power of $549 \mathrm{~kW}$ and GE Jenbacher JGS 312 GSB.LC with the electric power of $637 \mathrm{~kW}$. [1]

- The measurement was conducted in the following period: from 20.8.2014 to 19.9.2014 - 31 days in total

\section{Biogas station at location 3}

The last measurement was performed at location 3 (BS 3). This BS also forms an immediate part of the collective farm enterprise dealing both with livestock and crops production. The extraction of biogas is also based on wet fermentation with the raw material represented by maize silage and farmyard slurry. These are supplied from the said collective farm enterprise. Electric power and heat are generated using three cogeneration units (CGUs) made by Schnell, fitted with Scania combustion engines. The total installed electrical capacity of the BS is $750 \mathrm{~kW}$ ( $2 \times K G J$ with the electrical power of $265 \mathrm{~kW}$ and $1 \times K G J$ delivering the electrical power of $250 \mathrm{~kW}$ ).

- The measurement was conducted in the following period: from 20.8.2015 to 19.9.2015 - 31 days in total

\section{CREATING A DATABASE OF MEASUREMENT}

The method described above yielded large amounts of data. The initial processing of these data was done using software that comes with the measurement equipment. Comprehensive waveforms of individual variables depending on time were created with this software. Furthermore, the data were exported and processed using MS Office Excel 2007. STATGRAPHICS Centurion XV.II was subsequently used for the statistical evaluation. An example of a part of thus created database is shown in Fig. 3. [3]

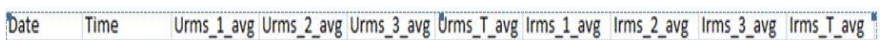

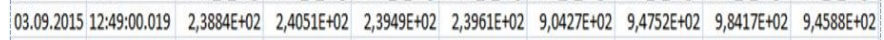

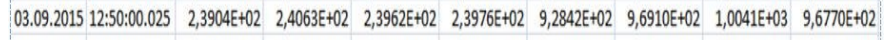

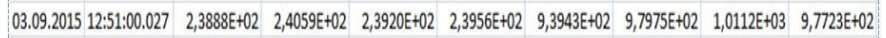

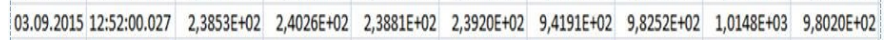

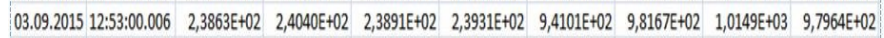

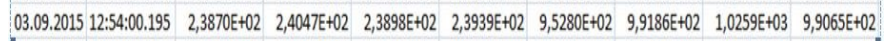

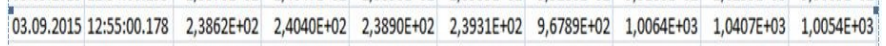

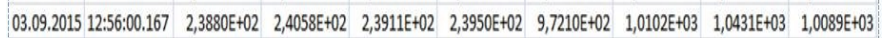

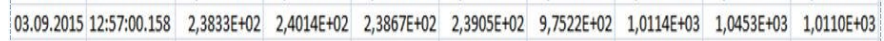

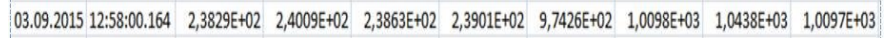

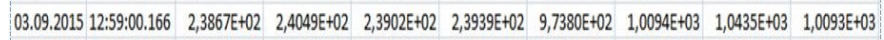

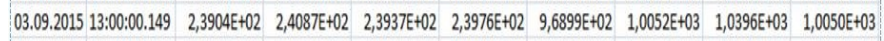

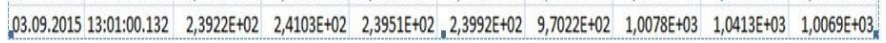
Fig. 3. Sample of database of measured data
\end{abstract}

\section{ASSESSMENT OF THE DATA MEASURED}

The next part of this paper deals with the analysis of course data obtained, with special regard to voltage, current, active power and reactive power data. Figs 4 to 6 demonstrate the course of the entire active power $(\mathrm{P})$ from the individual BSs measured. The total three-phase active power $(\mathrm{P})$ is then equal to the sum of power ratings of individual phases $(\mathrm{P} 1+\mathrm{P} 2+\mathrm{P} 3)$. 


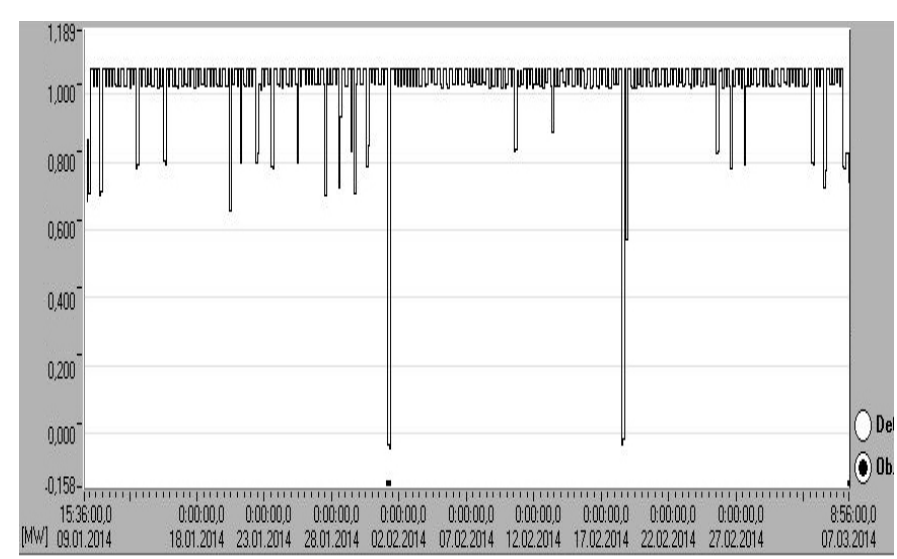

Fig. 4. Course of entire active power over the whole period observed at the location of BS 1

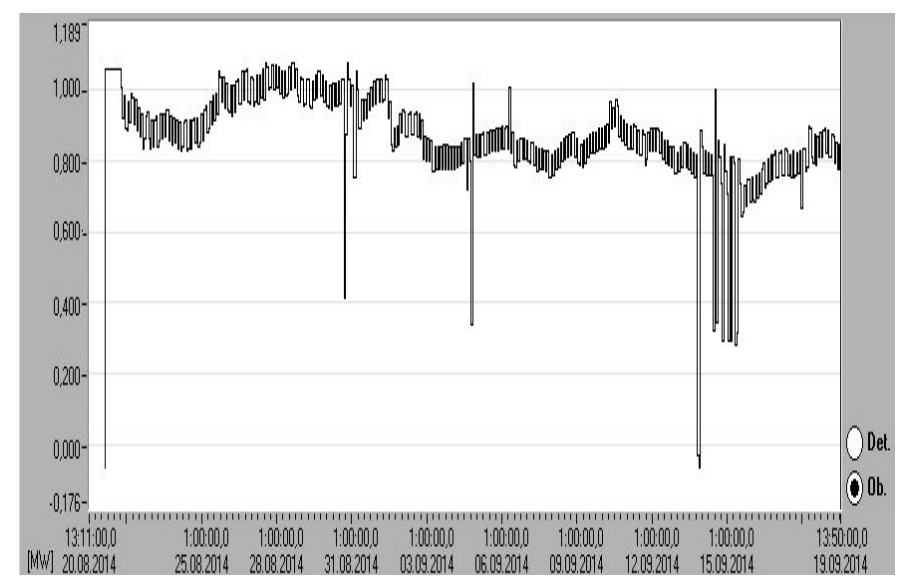

Fig. 5. Course of entire active power over the whole period observed at the location of BS 1

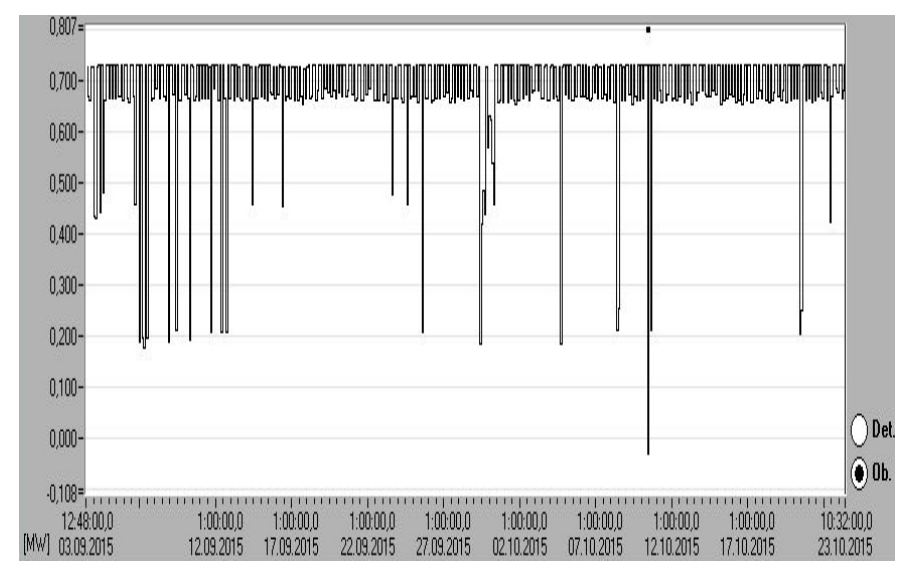

Fig. 6. Course of entire active power over the whole period observed at the location of BS 3

The graphs of active power and the chart depicted here also show that operation of all three BSs encountered black outs or drops of power supplied to the grid. All these BSs show basically the same nature of these drops of the power supplied or black outs, as the case may be. The total duration of these black outs or drops is almost negligible with respect to the total operation time, it ranges between approximately 3,5 and 73,7 hours, representing approx. $0,5-5,4 \%$ of the total operation time of CGU in individual BSs. As far as this period is concerned, individual stations would suffer approx. 2,7-69 min. of total power black outs (approx. $0.004-0.084 \%$ of the total operation time of individual BSs).

The stability of CGUs at individual biogas stations implies that the supply of electric power is stable and predictable. This is evident mainly during operation of BS 1 and BS 3. These two BSs operated in a fairly stable manner throughout the majority of measurement period, their active power ranged within values approximating the nominal values. The only unit showing larger fluctuation of the output active power was BS 2 . However, this fluctuation was mainly due to the incorrect control of BS, i.e. the failure to obey procedures to feed the fermented material.

\section{A. Total black out of the active power $(P)$ supply}

Each total black out resulted in a step change of the active power from the regular operating level to the zero supply values. All three biogas stations were disconnected from the grid upon the black out, so no values could be measured. The resumed operation then brought gradual rise of the supplied power up to the regular operating level. The average time to restoration of regular operation after the black out of all CGUs was below 10 minutes at each BS. However, total black outs of CGUs are a very rare phenomenon.

\section{B. Total black out of the active power (P) supply}

Another condition occurring during the operation more frequently than total black outs was the drop of supplied power, as mentioned above. As far as the nature of their course was concerned, these drops showed identical characteristics at all three BSs. These drops were characteristic for reduction of the active power of around $100-350 \mathrm{~kW}$. The apparent major cause of these drops was represented by shutdown of one or more CGUs for either operating (insufficient volume of biogas generated) or technical (failure/outage) cause. Since each of the BSs mentioned above is provided with a different number and type of co-generation units, the output power available during such drops actually differs.

The Table No. 1 below shows the basic statistical data describing operation of all three co-generation units, i.e. the data includes basic details about the power supply to the grid.

The entire measurement period showed significant fluctuations of grid voltage at all three BSs. The voltage course characteristics of this fluctuation were identical for all three stations and not affected by the operation of CGUs. For demonstration of the voltage course see Fig. 7.

The magnitude of voltage fluctuation was characterized by values from approx. $227 \mathrm{~V}$ to $245 \mathrm{~V}$, i.e. with the total range of about $15.5 \mathrm{~V}$. The maximum and minimum deviations of voltage therefore did not exceed the limits defined for the relevant standard $( \pm 10 \% \mathrm{Un})$; meaning values within the range from $207 \mathrm{~V}$ to $253 \mathrm{~V}$. 
TABLE I

BASIC INFORMATION OF CGUS OPERATION

\begin{tabular}{|l|c|c|c|}
\hline \multicolumn{4}{|c|}{ Basic Information of CGUs Operation } \\
\hline $\begin{array}{c}\text { Basic Information on Power } \\
\text { Supply }\end{array}$ & BPS 1 & BPS 2 & BPS 3 \\
\hline Total measurement period (h) & 1361 & 693,1 & 1197,97 \\
\hline $\begin{array}{l}\text { Total period of decreased power } \\
\text { supply (h) }\end{array}$ & 73,7 & 3,5 & 46 \\
\hline $\begin{array}{l}\text { Total period of full power failures } \\
\text { (h) }\end{array}$ & 1,15 & 0,25 & 0.045 \\
\hline $\begin{array}{l}\text { Trouble-Free Operation } \\
\text { (no black out or power failures) }\end{array}$ & 1287,3 & 689,6 & 1151.97 \\
\hline Full supply power failure & 2 & 1 & 1 \\
\hline
\end{tabular}

Further findings also revealed a certain imbalance of voltage between individual phases. The difference between voltage levels at particular phases amounted up to approx. $2 \mathrm{~V}$. This imbalance was then projected at all three BSs to a more or less extent. (Fig.8)

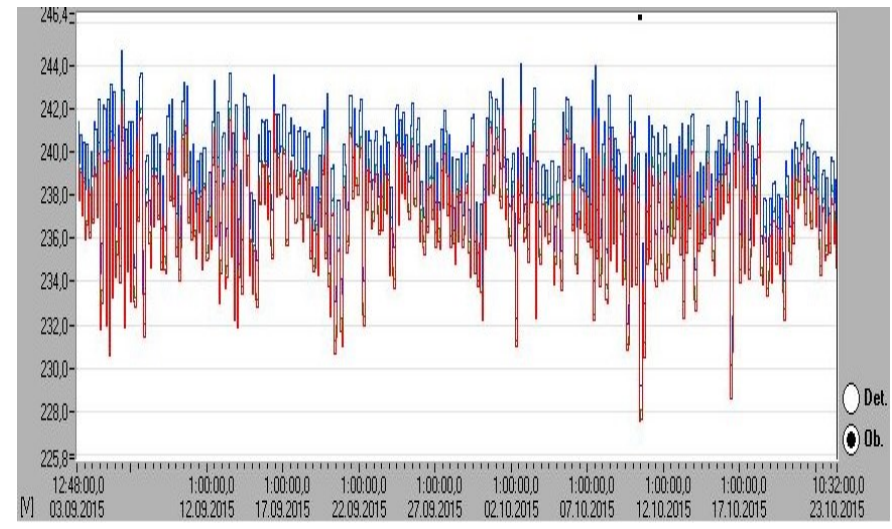

Fig. 7. Course of voltage at BS 3 (colors - individual phases)

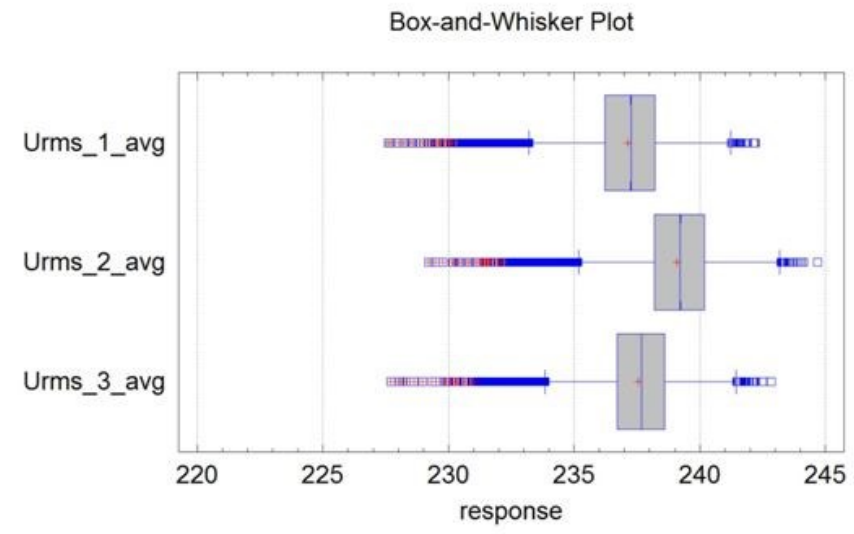

Fig. 8. Box plot of individual phase voltages

\section{EVALUATION OF ELECTRIC POWER QUALITY}

As already mentioned in the introductory part, each measurement conducted on particular BS was accompanied by evaluation of electric power quality in compliance with CSN EN 50160.
The outcomes of measurement then imply that the network parameters as the frequency, flicker and voltage unbalance complied with conditions given by the relevant standard and applicable to all three BSs subject to measurement. The spectra of harmonics of higher degree and currents were almost identical for all the BSs measured. Figs 9 and 10 show the sample spectrum of harmonic voltage of higher levels with designated permitted limits in accordance with CSN EN 50160 applicable to BS 2.

None of the limits were exceeded, the values approximating these limits are the fifth and seventh harmonics, which exceed a half of the limits permitted. Fig. 9 shows the spectrum of harmonic current of higher levels from the first (basic) up to the fiftieth harmonic. The only features visible throughout the entire spectrum are harmonics of lower levels, i.e. the second, the third, the fourth, the fifth, the sevenths and the eleventh one. Since the spectrum of higher degree harmonics show degrees above the spectrum of harmonic currents caused mainly by synchronous generators in co-generation units, these higher degrees of voltage are most likely dragged in form the superior $22 \mathrm{kV}$ grid.

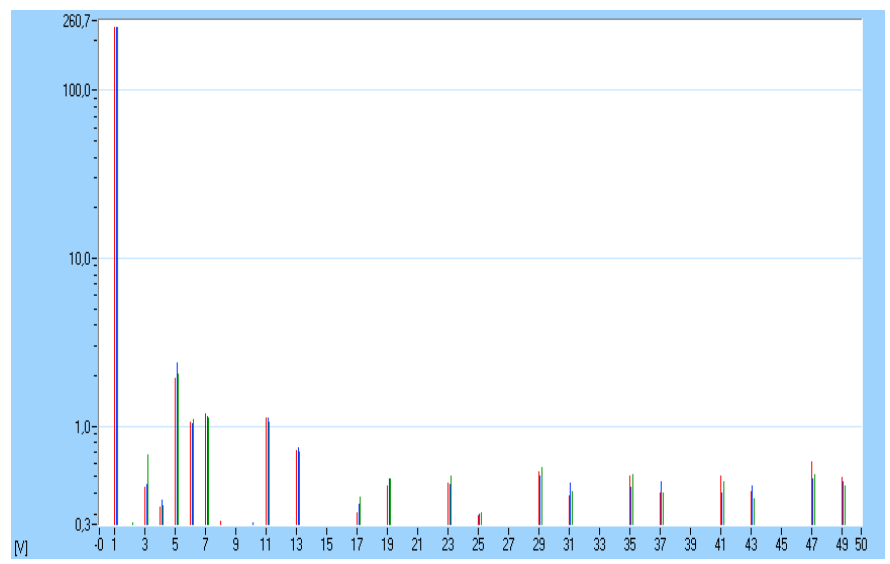

Fig. 9. Spectrum of harmonic voltage of higher levels with designated permitted limits in accordance with CSN EN 50160 - BPS2

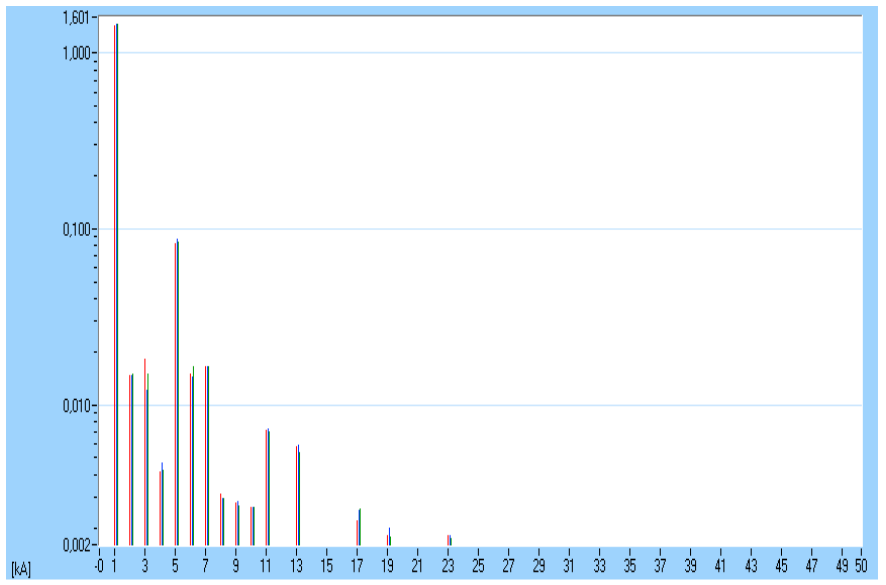

Fig. 10. Spectrum of harmonic current of higher levels with designated permitted limits in accordance with CSN EN 50160 - BS 2 


\section{EVALUATION OF BS MEASUREMENT RESULTS}

As far as the operation of all three BSs is concerned, the measurement has proven these sources of electric power as strongly stable. As already mentioned above, these do not show any negative parameters with respect to the electric power quality either. The comparison relating to operation of individual BSs has not disclosed any significant differences. These stations were almost identical with respect to the nature of both their operation and their black outs. When compared to the remaining two BSs, the greatest differences were shown by BS 2 .

The operation of all three CGUs shows drops or black outs of electric power. The apparently most frequent reason for full failures of all CGUs at a particular BS was the very configuration of CGU protection features, which mostly respond to extraordinary phenomena in the grid (voltage/undervoltage). These short-term changes could not be recorded owing to the measurement sampling characteristic (1 $\min )$.

However, there are more and more occasions with the drop of electric power supply to the grid during operation. The review of operating logs available for particular BSs clearly shows three potential causes of this operating condition. The apparently most frequent cause is the insufficient generation of biogas during the fermentation process or even its low quality. The other one would be regular technical attitudes to maintenance and unexpected black outs due to a technical problem.

The simplest method to reduce drops in electric power production would be to exclude falls caused by insufficient generation of biogas. This problem is associated with the technical procedures during fermentation but the option to store the biogas produced in particular. Storage of biogas produced, i.e. keeping its stock for periods of insufficient production, relates to the volume of gas tank. The vast majority of existing BSs within the territory of Czech Republic has been designed for uninterrupted operation, i.e. the biogas produced is consumed by CGUs almost immediately. In case the volume of biogas generated is excessive or if one or more CGUs have failed, the biogas cannot be stored and it must be combusted on the safety burner (flare), which seems highly uneconomical. This problem can be potentially resolved by construction of new gas tanks or even extension of storage space inside fermentation tanks. Biogas stored in these facilities could be then used to compensate for production lacks or higher demand for electric power or heat.

\section{CONCLUSION}

The aim of this paper was to find reminiscence in the course of power supplied from individual BSs or even to explain the causes of black outs with the attempt to suggest a way for their further elimination.

The results obtained by measurement show the high reliability of electric power supply to the grid (the duration of black outs per BS is equal to approximately $0.0029 \%$ of the operating hours). The supply of electric power from co- generation units combusting biogas can be therefore generally described as very stable and also easily predictable as a renewable energy resource. The greatest impact on power supply is seen at quality, that is the lack of biogas supplied (percentage of methane $\mathrm{CH} 4$ in biogas), strongly dependent on the quality of primary (organic) product.

This paper also serves as a source of information about stability of output from co-generation units for further research. The research will deal with cooperation among other renewable resources of electric power (solar or wind power plants) and present an opportunity for stabilization of the power supplied to $22 \mathrm{kV}$ grids. The last but not the least purpose of this paper is to contribute towards potential utilization of the BS for storage of electric power for its future re-use during emergency situations in the grid, for example black-outs.

\section{REFERENCES}

[1] L. Novosad, Z. Hradilek, "Power Analysis of Co-Generation Units at Biogas Station", Proceedings of the 16th International Scientific Conference on Electric Power Engineering (EPE) 2015 Dlouhé Stráně, 2015, ISBN 978-1-4673-6788-2

[2] L. Novosad, Z. Hradilek, P. Moldř́k, "Analysis of data measured in Tosanovice biogas station", ELNET 2015: $12^{\text {th }}$ workshop : Ostrava, $24^{\text {th }}$ November 2015, pp. 28-36

[3] M. Dummer, M. Litschmannova, "Statistika I.". Statistika I. VSB Technical university of Ostrava, 1997, 80-7078-496-2

[4] Z. Hradílek, "Elektroenergetika průmyslových a distribučnich zařizení," 1.vyd. VŠB - TU Ostrava. 2008. ISBN 978-80-7225-291-6.,p.315, 2008.

[5] L. Novosad, Z. Hradilek, "Analysis of Energy Balances Three Biogas Stations in Czech Republic", Proceedings of the 16th IEEE International Conference on Environment and Electrical Engineering, 2016 